\title{
Analiza przyczyn uszkodzeń płytki blokowanej kompresyjnej stabilizującej ztamanie końca dalszego i części dalszej trzonu kości piszczelowej
}

\section{Causes of damage to the locking compression plate stabilizing the fracture of the distal tibia and distal end of the tibia}

\author{
Jacek Lorkowski1, ${ }^{\circledR}$, Mirosław M. Mrzygłód³ ${ }^{3}$ Oliwia Grzegorowska², Ireneusz Kotela \\ ${ }^{1}$ Centralny Szpital Kliniczny MSW w Warszawie, Klinika Ortopedii i Traumatologii, ul. Wołoska 137, 02-507 Warszawa \\ ${ }^{2}$ Centrum Rehabilitacji „Zdrowie” w Krakowie, ul. św. Gertrudy 28, 31-048 Kraków \\ ${ }^{3}$ Politechniki Opolska, Katedra Mechaniki i Podstaw Konstrukcji Maszyn, ul. Mikołajczyka 5, 45-271 Opole \\ $\triangle$ jacek.lorkowski@gmail.com
}

\begin{abstract}
Introduction: Implant damage is one of the complications of fracture treatment.

Case report: In this paper we present the case of a 59-year-old patient after surgical treatment of the distal tibia and distal end of the tibia fracture with multiple bone fragmentation (AO 43C3). The implant damage was caused not only by the patient's noncompliance, but also by the notch effect and fatigue fracture of
\end{abstract}

the locking compression plate (medial distal tibial plate), most probably secondary to technological error (macroscopic and FEM analysis).

Conclusion: The presented case shows that the patient's compliance and elimination of construction and production errors are necessary to achieve satisfactory treatment effects.

Keywords: tibial fracture; in silico analysis; metal fatigue; finite element method; damage control.

\begin{abstract}
ABSTRAKT
Wstęp: Uszkodzenia implantów są jedną z przyczyn powikłań w leczeniu złamań.

Opis przypadku: W pracy przedstawiono przypadek 59-letniego chorego, u którego po leczeniu operacyjnym wieloodłamowego złamania końca dalszego i części dalszej trzonu kości goleni (wg klasyfikacji AO 43C3) doszło do uszkodzenia implantu nie tylko z powodu braku współpracy chorego, ale również w wyniku powstania zjawiska karbu i złamania zmęczeniowego płytki blokowanej kompresyjnej (locking compression plate - medial
\end{abstract}

distal tibial plate), prawdopodobnie z powodu błędu technologicznego (analiza makroskopowa i metoda elementów skończonych). Wniosek: Przedstawiony przypadek dowodzi konieczności współpracy z chorym w trakcie leczenia złamań oraz konieczności wyeliminowania błędów konstrukcyjnych i produkcyjnych używanych implantów.

Słowa kluczowe: złamanie kości piszczelowej; analiza in silico; zmęczenie metalu; metoda elementów skończonych; kontrola obrażeń.

\section{WSTĘP}

Uszkodzenia implantów są jedną z przyczyn powikłań w leczeniu złamań, co powoduje konieczność wykonywania dodatkowych zabiegów operacyjnych oraz wydłuża całkowity czas terapii i okres niezdolności do pracy [1].

Celem pracy była analiza przyczyny uszkodzenia płytki blokowanej kompresyjnej (LCP) użytej do stabilizacji wieloodłamowego złamania końca dalszego i części dalszej trzonu kości goleni lewej.

\section{OPIS PRZYPADKU}

Pacjent K.W., lat 59, został przyjęty do kliniki z powodu wieloodłamowego złamania końca dalszego i części dalszej trzonu

kości piszczelowej oraz strzałkowej lewej (wg klasyfikacji AO ${ }_{43} \mathrm{C}_{3}$ ) - rycina 1 - doznanego w mechanizmie urazu wysokoenergetycznego (pieszy w stanie upojenia alkoholowego potrącony przez samochód). Oprócz widocznego w radiogramie wieloodłamowego złamania stwierdzono badaniem fizykalnym rozległe stłuczenie skóry i tkanek miękkich z ogniskami martwicy oraz zaburzeniami ukrwienia na obwodzie.

Chorego operowano w trybie doraźnym. Nie uzyskano jego zgody na czasowe założenie stabilizatora zewnętrznego. W związku z tym, u chorego operowanego w trybie damage control, doraźnie kość piszczelową zespolono płytką LCP dedykowaną dla końca dalszego i trzonu kości piszczelowej (medial distal tibial plate), wprowadzając materiał zespalający z kilku niewielkich cięć, zgodnie z zasadami kontroli obrażeń (damage control) i chirurgii małoinwazyjnej (minimally-invasive surgery). Ze względu na częściowe zniszczenie 

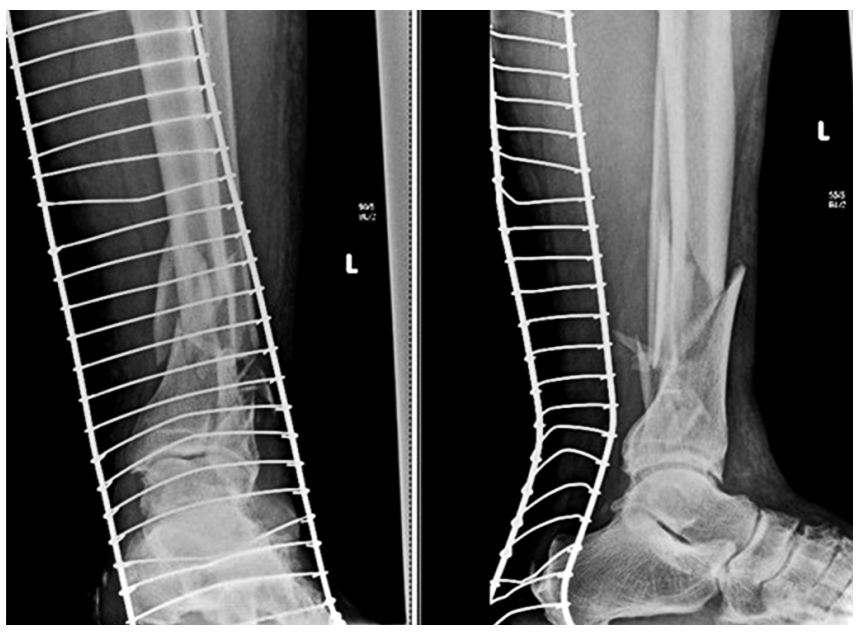

RYCINA 1. Wieloodłamowe złamanie końca dalszego i części dalszej trzonu kości piszczelowej i strzałkowej lewej (radiogram w projekcji przednio-tylnej i bocznej) wg klasyfikacji AO 43C3

tkanek miękkich po stronie przedniej goleni nie korygowano w pełni jej tyłowygięcia, gdyż powodowało to widoczne śródoperacyjnie niedokrwienie (m.in. stłuczony przedni pęczek naczyniowo-nerwowy goleni). Złamanie strzałki zespolono płytą Osteo (ryc. 2). Następnie kończynę dodatkowo unieruchomiono w łusce gipsowej stopowo-goleniowej. Po zabiegu stwierdzono prawidłowe ukrwienie i unerwienie na obwodzie. Wdrożono farmakoterapię (antybiotykoterapia, profilaktyka przeciwzakrzepowa, leczenie naczynioprotekcyjne, przeciwbólowe, przeciwobrzękowe) oraz działania terapeutyczne zgodnie $\mathrm{z}$ algorytmem P.R.I.C.E. (protection, rest, ice, compresion, elevation) [2]. Wykonany po zabiegu radiogram wskazywał na akceptowalną, po uwzględnieniu całości stanu klinicznego, repozycję złamania.

Kilkadziesiąt minut po zabiegu chory bez zgody personelu wstał i zaczął chodzić, w pełni obciążając kończynę operowaną. Następnie, w ciągu kilku godzin, u chorego wystąpiły pełne objawy majaczenia alkoholowego. Został on przekazany w trybie doraźnym do dalszego leczenia w warunkach oddziału psychiatrycznego z zaleceniami ortopedycznymi, dotyczącymi dalszego postępowania.
W czasie kontroli ortopedycznej, do której chory zgłosił się dopiero po 4 tyg. od zabiegu, stwierdzono dalsze nieprzestrzeganie zaleceń oraz nie w pełni wygojone, brudne rany. Na kontrolnym radiogramie uwidoczniono plastyczne odkształcenie płyty stabilizującej złamanie (ryc. 3), tj. częściowe uszkodzenie zespolenia, które w dużym stopniu utraciło swoje własności biomechaniczne. Zmianę krzywizny (wygięcie) implantu stwierdzono dokładnie w miejscu, gdzie wystąpiło uszkodzenie konstrukcji.

Po 7 tyg. od stabilizacji złamania, u chorego, który nadal nie przestrzegał zaleceń, doszło do pęknięcia płyty LCP (tzw. przełom zmęczeniowy) - ryciny 4 i 5 . Podczas badania makroskopowego stwierdzono charakterystyczne strefy rozwoju pęknięcia zmęczeniowego. Obraz przełomu wskazywał, że inicjacja szczeliny zmęczeniowej nastąpiła na brzegu niegwintowanego otworu. Obraz powierzchni wskazywał, że szczelina zmęczeniowa rozwijała się w trakcie cyklicznego obciążenia konstrukcji, aż do momentu wyczerpania nośności granicznej przekroju, po osiągnięciu której nastąpiło pęknięcie kruche (charakteryzujące się matowym obrazem przełomu) - ryciny 6 i 7. Z punktu widzenia stwierdzonych znacznych odkształceń plastycznych konstrukcji proces zmęczenia materiału dla badanego obiektu określono jako zakres niskocyklowy $\left(10^{3}-10^{4}\right.$ cykli) $[3,4,5]$. W obrazie klinicznym jednoczasowo wytworzyły się przetoki wskazujące na proces zapalny. Potwierdzały to wyniki badań laboratoryjnych.

W trakcie leczenia podjęto analizę symulacyjno-wytrzymałościową płyty LCP wykonanej ze stopu Cr-Ni-Mo X X2CrNiMo17-13 (AISI 316L) [6]. Dla celów tej analizy wykonano w programie CATIA V5 model geometryczny CAD 3D badanego obiektu. W kolejnym kroku zaimportowano model CAD do modułu do analizy metodą elementów skończonych (MES) CATIA/GSA [7]. W module tym dokonano dyskretyzacji modelu 3D oraz wykonano dodatkowo model kości piszczelowej. W modelu MES kość została odtworzona w sposób uproszczony jako konstrukcja homogeniczna o właściwościach izotropowych z uwzględnieniem miejscowego zmniejszenia sztywności wynikającego ze złamania. Płyta LCP została natomiast zamodelowana z dokładnością pozwalającą na precyzyjną analizę konstrukcji. Dla założonego modelu MES oraz przyjętej

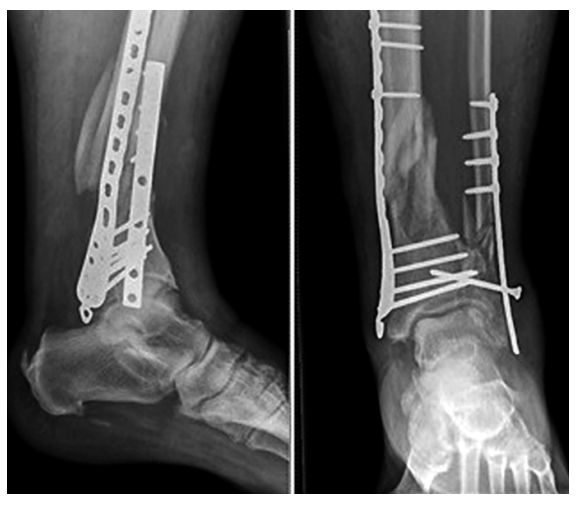

RYCINA 2. Obraz radiologiczny goleni po złamaniu, w trakcie kontroli, 4 tyg. od zabiegu operacyjnego (widoczne m.in. plastyczne odkształcenie płyty LCP stabilizującej złamanie)

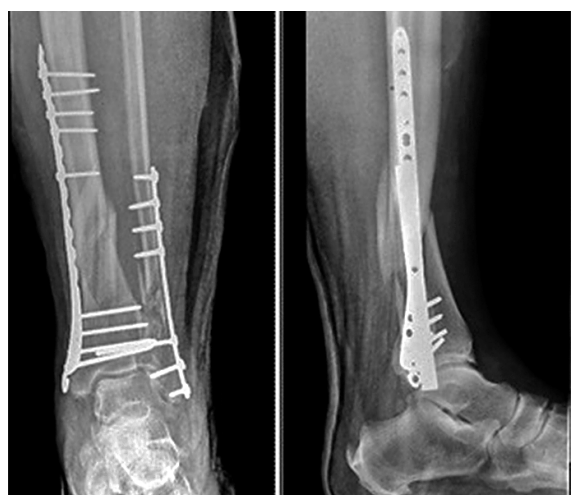

RYCINA 3. Obraz radiologiczny po stabilizacji złamania płytą LCP (kość piszczelowa) i Osteo (kość strzałkowa)

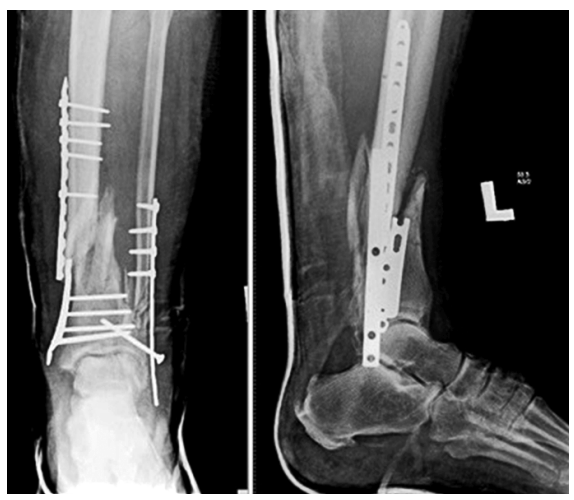

RYCINA 4. Obraz radiologiczny goleni po złamaniu, w trakcie kontroli, 4 tyg. od zabiegu operacyjnego (widoczne m.in. ztamanie płyty LCP stabilizującej ztamanie) 

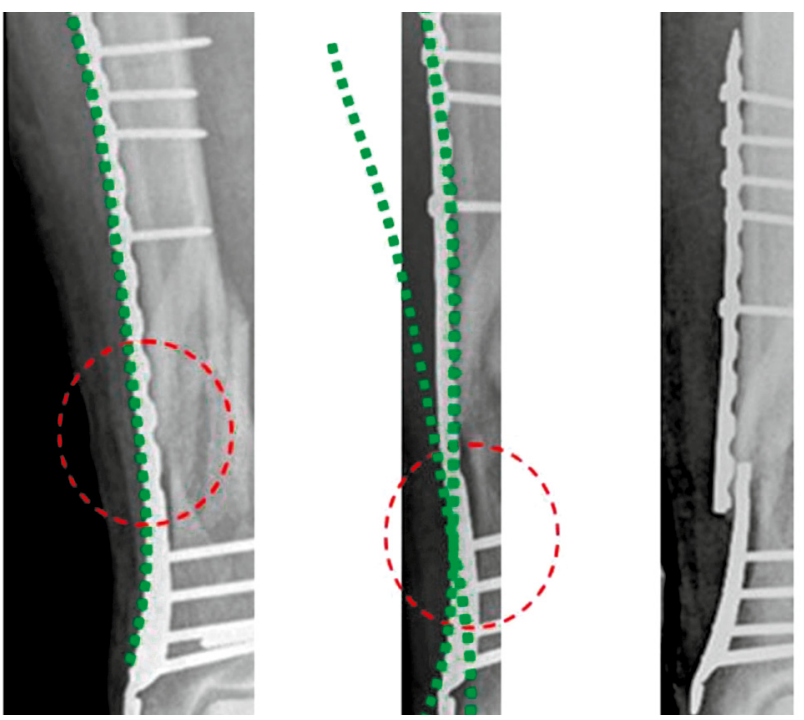

RYCINA 5. Ewolucja plastycznego odkształcenia implantu - płyty LCP (od strony lewej kolejno obrazy: po zespoleniu złamania, po 4 tyg. od ztamania, po 7 tyg. od złamania) - na zielono zaznaczono prawidłowy i rzeczywisty kontur implantu
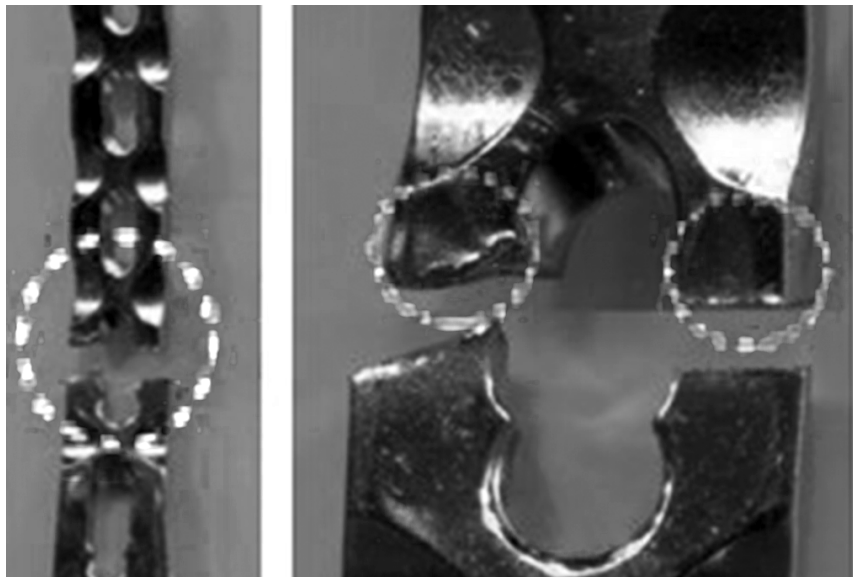

RYCINA 6. Inicjacja szczeliny zmęczeniowej na brzegu niegwintowanego otworu płyty LCP - obraz makroskopowy
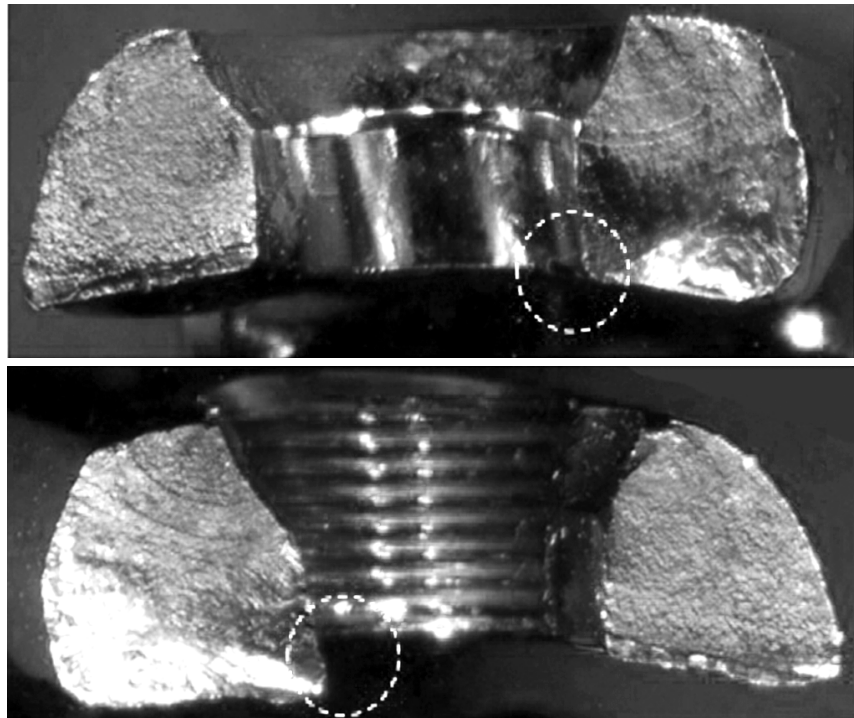

RYCINA 7. Charakterystyczne strefy rozwoju pęknięcia zmęczeniowego matowy obraz przełomu właściwości materiałowej odpowiadającej stali X2CrNiMo17-13 wykonano analizę wytrzymałościową w oparciu o uproszczony schemat obciążenia. Do badań przyjęto, że kość będzie obciążona masą ciała w pozycji stojącej, co z uwagi na miejscowe osłabienie fragmentu kości wywoła moment zginający. Wynik analizy komputerowej potwierdził hipotezę opartą na oględzinach zdjęć implantu co do miejsca lokalizacji uszkodzenia oraz występowania w nim koncentracji naprężeń (ryc. 8).

W trakcie dalszego leczenia choremu usunięto zespolenie, wycięto przetoki, następnie założono stabilizator zewnętrzny „Zespol” oraz wdrożono antybiotykoterapię zgodnie z antybiogramem. W związku z normalizacją stanu psychicznego możliwa stała się współpraca z chorym. Uzyskano wygojenie procesu zapalnego (zamknięcie przetok, wygojenie ran, normalizacja CRP) oraz zrost złamania.

\section{DYSKUSJA}

Przebieg leczenia wskazywał, że z punktu widzenia klinicznego podstawową przyczyną obluzowania zespolenia (zmęczeniowego uszkodzenia implantu) był brak współpracy chorego, nieprzestrzeganie jakichkolwiek zaleceń, a także obciążanie kończyny bezpośrednio po zabiegu operacyjnym. Dodatkowo, ze względu na brak zgody chorego na zabieg w trybie

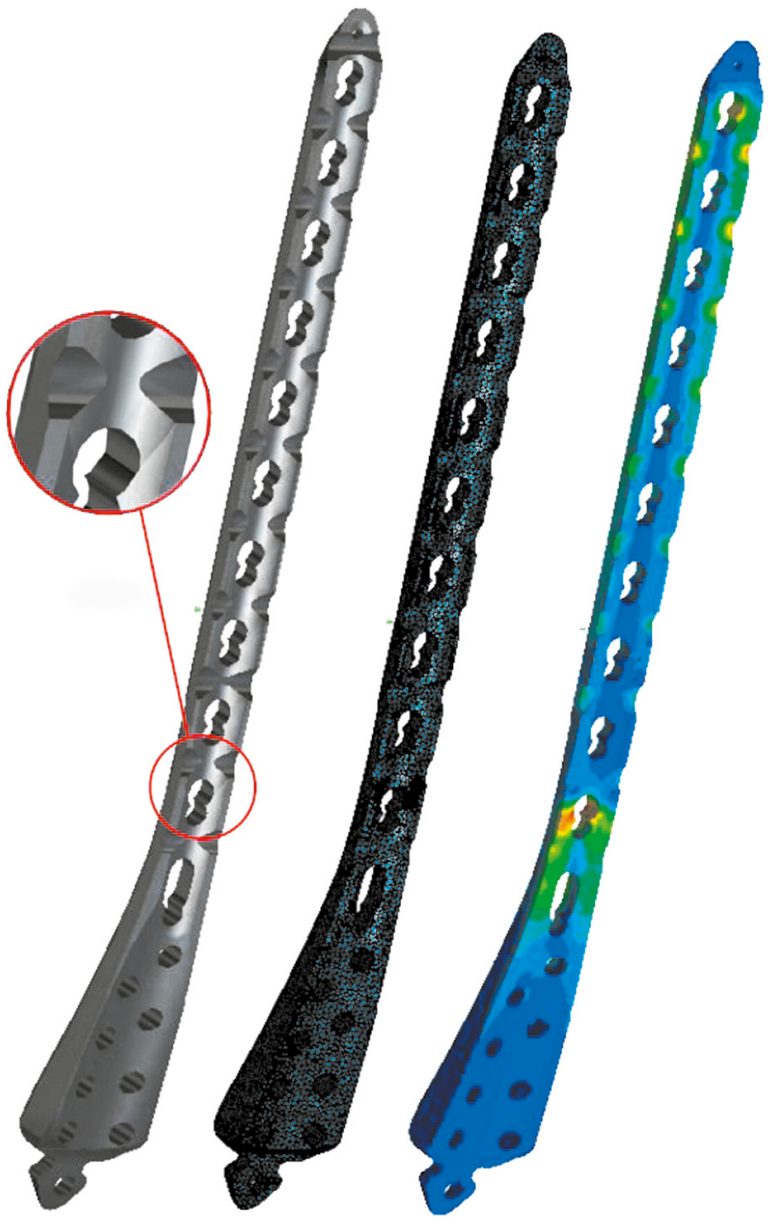

RYCINA 8. Analiza MES implantu - kolejno od strony lewej: model CAD 3D; model MES; mapa konturowa naprężeń w okolicy wystąpienia uszkodzenia 
damage control, wykonano nie tak, jak wstępnie zaplanowano, tj. z pierwotną, czasową stabilizacją złamania stabilizatorem zewnętrznym, a następnie wtórną osteosyntezą z odtworzeniem w pełni stosunków anatomicznych. Został więc zastosowany sposób leczenia chirurgicznego, który przez autorów nie był uważany za optymalny.

Brak współpracy chorego w omawianym przypadku wynikał z wystąpienia zespołu, określanego w nomenklaturze psychiatrycznej jako zespół majaczeniowy w przebiegu zespołu abstynencyjnego. Towarzyszył mu napad drgawek, który dodatkowo zwiększał siły działające na implanty stabilizujące złamanie. Zgodnie z piśmiennictwem, do czynników biorących udział w powstawaniu majaczenia alkoholowego zalicza się przede wszystkim nagłe zaprzestanie picia alkoholu, zwłaszcza po długotrwałym ciągu picia, a także inne czynniki, np. urazy lub infekcje. U przedstawionego pacjenta wystąpiły dwa z nich. Spowodowało to wystąpienie triady objawów charakterystycznych dla majaczenia alkoholowego, tj. pojawienie się zaburzeń świadomości, silnych drżeń mięśniowych oraz omamów i złudzeń wzrokowych [8]. Występowanie tego typu patologii zawsze stanowi zagrożenie dla życia pacjenta oraz wyniku leczenia ortopedycznego, co miało miejsce w omawianym przypadku.

Analiza konstrukcji płyty LCP wykazała występowanie na jej wewnętrznej powierzchni anomalii stereometrycznej, która jest potencjalnym źródłem lokalnego obniżenia trwałości zmęczeniowej (powstawanie efektu karbu i lokalnej koncentracji naprężeń). Występowanie anomalii stereometrycznej charakteryzuje się obecnością na powierzchni wewnętrznej implantu tzw. garbków. Są one wynikiem nałożenia dwóch operacji technologicznych wykonywania wewnętrznych żłobień przez frezowanie/szlifowanie kształtowe. Operacje te wykonywane są zgodnie z dwiema krzywymi kierującymi, które „spotykają się” dokładnie w miejscu, gdzie występują anomalie stereometryczne. Występowanie zjawiska karbu na powierzchni implantu powoduje lokalny wzrost naprężeń, który jest odpowiedzialny za inicjację szczeliny zmęczeniowej $[9,10]$. Ze zjawiskiem takim autorzy mieli do czynienia w opisywanym przypadku. Trwałość i niezawodność płyty LCP mogłaby zostać zwiększona przez zmiany w technologii produkcji prowadzące do wyeliminowania niewykrywanych błędów konstrukcyjnych lub produkcyjnych.

\section{WNIOSEK}

Przedstawiony przypadek dowodzi konieczności współpracy z chorym w trakcie leczenia złamań, ale również wyeliminowania błędów konstrukcyjnych i produkcyjnych używanych implantów.

\section{PIŚMIENNICTWO}

1. Lorkowski J, Juras B, Kozień M, Hładki W, Trybus M. Analiza metrologiczna uszkodzeń materiału zespalającego przy stabilizacji złamań metodą AO. Przegl Lek 2012;69(6):222-8.

2. Petersen W, Rembitzki IV, Koppenburg AG, Ellermann A, Liebau C, Brüggemann GP, et al. Treatment of acute ankle ligament injuries: a systematic review. Arch Orthop Trauma Surg 2013;133(8):1129-41.

3. Kanchanomai C, Phiphobmongkol V, Muanjan P. Fatigue failure of an orthopedic implant - A locking compression plate. Engineering Failure Analysis 2008;15,521-30.

4. Mrzyglód M. Parametryczna optymalizacja konstrukcji pracujących przy obciążeniach wysokocyklowych, PhD Thesis. Kraków: Politechnika Krakowska; 2005.

5. Zahavi E, Torbilo V. Fatigue Design. Life Expectancy of Machine Parts, London: CRC Press; 1996.

6. Nassiri M, MacDonald B, O'Byrne JM. Computational modelling of long bone fractures fixed with locking plates - How can the risk of implant failure be reduced? J Orthop 2013;10(1):29-37.

7. Dassault Systèmes, CATIA V5.19 Documentation - Generative Structural Analysis; 2010.

8. Lutz UC, Batra A. Diagnostics and therapy of alcohol withdrawal syndrome: focus on delirium tremens and withdrawal seizure. Psychiatr Prax 2010;37(6):271-8.

9. Marcomini JB, Baptista CA, Pascon JP, Teixeira RL, Reis FP. Investigation of a fatigue failure in a stainless steel femoral plate. J Mech Behav Biomed Mater 2014;38:52-8.

10. Nassiri M, MacDonald B, O’Byrne JM. Locking compression plate breakage and fracture non-union: a finite element study of three patient-specific cases. Eur J Orthop Surg Traumatol 2012;22:275-81.

\section{KOMENTARZ REDAKCJI}

Redakcja publikuje niniejszą pracę mimo krytycznej recenzji. Jak z niej wynika, uszkodzenie powstałe w następstwie leczenia ortopedycznego było spowodowane wadliwą metodą chirurgiczną. Wychodzimy z założenia, że publikacja błędów terapeutycznych i powikłań, choć niepopularna, jest instruktywnym źródłem wiedzy w zakresie dobrej praktyki lekarskiej. 